\title{
Transport of infants with congenital heart disease
}

\author{
Althaf Ansary \\ Received: 4 August 2014 / Accepted: 8 October 2014 / Published online: 17 October 2014 \\ (C) Springer-Verlag Berlin Heidelberg 2014
}

I read the recent article [2] on transport of infants with congenital heart disease with interest. The authors report safer and less resource intense transfer of infants with congenital heart disease (CHD) who had antenatal diagnosis ( $\mathrm{ANdx}$ ) when compared to postnatal diagnosis in a retrospective cohort study over 5 years. It would be interesting to know whether infants in these two groups were contemporary or the $\mathrm{ANdx}$ group were more recent. There has been a significant improvement in ANdx of CHD in the last decade worldwide, and a study done from the same region has previously reported an annual improvement of $9 \%$ in the ANdx of CHD [1]. It is important to look for time trend as there is significant improvement in initial stabilisation and change in practice to non-invasive ventilation and permissive hypotension in most of the neonatal units in managing sick infants. This in turn will reflect on the subsequent respiratory support and cardiac therapies required during transport.

Conflict of interest None.

\section{References}

1. Chew C, Stone S, Donath SM, Penny DJ (2006) Impact of antenatal screening on the presentation of infants with congenital heart disease to a cardiology unit. J Paediatr Child Health 42(11):704-708

2. Gupta N, Leven L, Stewart M, Cheung M, Patel N (2014) Transport of infants with congenital heart disease: benefits of antenatal diagnosis. Eur J Pediatr 173(5):655-660

Communicated by Patrick Van Reempts

This paper is a correspondence for $<\mathrm{http}: / / \mathrm{dx}$.doi.org/10.1007/ S00431-013-2231-0>.

A. Ansary $(\bowtie)$

Paediatrics, Royal Alexandra Hospital, Paisley PA2 9PN, UK

e-mail: dralthaf_ansari@yahoo.com 